\title{
The Use of Moist Potential Vorticity Vector as Diagnostic Variable of Rainfall Events in Tanzania
}

\author{
Philbert Modest Luhunga ${ }^{1}$, Agnes Kijazi ${ }^{1}$, Ladislaus Chang'a ${ }^{1}$, Chuki A Sangalugembe ${ }^{2}$, Doreen Mwara \\ Anande ${ }^{2}$, Hashim $\mathrm{Ng}^{\prime}$ ong' olo $^{1}$, \& Habiba Mtongori ${ }^{1}$ \\ ${ }^{1}$ Tanzania Meteorological Agency, Research Section, Tanzania \\ ${ }^{2}$ Tanzania Meteorological Agency, Numerical Weather Prediction (NWP) Section, Tanzania \\ Correspondence: Philbert Modest Luhunga, Tanzania Meteorological Agency, Research Section, Tanzania. E-mail: \\ philuhunga@yahoo.com
}

Received: June 14, 2017

Accepted: July 8, 2017

Online Published: August 20, 2017

doi:10.5539/apr.v9n5p1

URL: https://doi.org/10.5539/apr.v9n5p1

\begin{abstract}
Abstarct
The work of this paper is a first step of the new paradigm, to use the Moist Potential Vorticity Vector (MPVV) as a diagnostic variable of rainfall events in Tanzania. The paper aims at computing and assessing the usefulness of MPVV in the diagnosis of rainfall events that occurred on $08^{\text {th }}$ and $09^{\text {th }}$ May 2017 over different regions in Tanzania. The relative contributions of horizontal, vertical components and the magnitude of MPVV on diagnosis of rainfall events are assessed. Hourly dynamic and thermodynamic variables of wind speed, temperature, atmospheric pressure and relative humidity from the numerical output generated by the Weather Research and Forecasting (WRF) Model, running at Tanzania Meteorological Agency (TMA) are used in computation of MPVV. The computed MPVV is then compared with WRF model forecasts and observed rainfall. It is found that in most parts of the country, particularly over coastal areas and North-Eastern Highlands, MPVV exhibited positive values in the lower troposphere $(925 \mathrm{hPa})$ and $(850 \mathrm{hPa})$ indicating local instability possibly associated with topographic effects, and continent/ocean contrast. MPVV is mostly positive with slightly negative values indicating instabilities (due to possible convective instability). Moreover, MPVV provides remarkably accurate tracking of the locations received rainfall, suggesting its potential use as a dynamic diagnostic variable of rainfall events in Tanzania.
\end{abstract}

Keywords: Moist Potential Vorticity Vector, Moist-air entropic potential temperature, Convective instability

\section{Introduction}

The economy of Tanzania largely depends on rain fed agriculture, hence there is an urgent need for better rainfall prediction in the country (Chang'a et al., 2010; Kijazi \& Reason, 2009). However, rainfall prediction over different regions of Tanzania is difficult due to several factors that contribute to its formation and distribution. These include, complex topographical terrain, numerous inland large water bodies, variation in vegetation types, land-ocean contrasts, planetary waves (Rossby waves), tropical waves (Madden-Julian oscillation), atmosphere-ocean interactions (El Niño-Southern Oscillation) and atmospheric-land-ocean interactions (Inter Tropical Convergence Zone) (Zhang, 2013; Schneider et al., 2014). Many physical processes that contribute to the formation and distribution of rainfall associated with the aforementioned factors are not well known and hence difficult to be modeled explicitly in prediction models. As a result the contemporary weather and climate models suffer a pitfall to predict rainfall over different regions in Tanzania.

In order to improve the skills of weather and climate models to predict rainfall, it is important to understand physical processes on formation of rainfall from local and large scale atmospheric circulations and parameterize them in weather and climate models. However, this can be limited by understanding of all physical process involved in the formation and distribution of rainfall and availability of computing facilities that can compute the highest resolution weather and climate models (with all physical parameterizations from local to large spatial scales). An alternative approach is to derive certain physical variable that combine the influence of large and local scales atmospheric flows on the formation and distribution of rainfall. Physical variable such as potential vorticity (PV) which is conserved as it moves across grid points and obeys invertibility principles can be used to describe the impact of large and local scale features on the formation and distribution of rainfall. 
The concept of PV has a long standing history in the study of fluid dynamics. It has been used in meteorology and oceanography for many years back; dating the work of pioneers such as (Bjerknes, 1898a,b, Rossby, 1939; Ertel, 1942). This concept has many applications in meteorology, oceanography and aerodynamics, for detailed review on the usefulness of this concept, the reader may consult Hoskins et al. (1985). PV can be used to explain all dynamic and thermal conditions of atmospheric flow on scales smaller than meso-scale. Indeed, PV can capture all the dynamics and thermal conditions of the atmospheric flow to the lower limit to the fineness of the structures that may occur, all the way down to the length scales on which molecular diffusion acts (Hoskins et al., 1985). Furthermore, PV is a fundamental physical variable in understanding atmospheric balanced flow and basic dynamical processes (McIntyre, 2015). Many important synoptic scale processes can be understood within the framework of PV (Hoskins et al, 1985). PV is conservative and is subject to inevitability principle for adiabatic reversible and frictionless motion of dry air (Marquet, 2014). It carries all the necessary dynamic information about the balanced wind and mass fields. In other words, PV distribution and suitable temperature distribution at the lower atmosphere boundary is sufficient to deduce, diagnostically, all other dynamical fields such as winds, temperature, geopotential heights, static stabilities and vertical velocities, under a suitable balance condition. According to Haynes and McIntyre (1986), even under diabatic heating, frictional and other forces, PV cannot be transported across any isentropic surface, it can neither be created nor destroyed within a layer bounded by two isentropic surfaces but it can be advected as a conserved scalar quantity.

In spite of the fundamental usefulness of the 'PV thinking', already described above, it has not yet been used in operational weather forecasting community. There are many possible reasons for this, including firstly, a lack of awareness of the utility of PV in atmospheric studies and secondly, lack of diagnostic studies that can demonstrate that PV can provide useful information that is difficult to obtain via more traditional means. The main purpose of this paper is to address the second reason.

The PV function of any real atmospheric variable $\psi$ may be defined as

$$
P V(\psi)=\rho^{-1} \zeta_{a} \cdot \nabla(\psi)
$$

, where $\rho$ density of air, $\zeta_{a}$ is the absolute vorticity and $\nabla(\psi)$ is three dimensional gradient of $\psi$.

The prognostic equation of $\mathrm{PV}$ in a hydrostatic atmosphere is written as

$$
\rho \frac{d}{d t}[P V(\psi)]=\frac{1}{\rho^{2}} \nabla(\psi) \cdot[\nabla(\rho) \times \nabla(p)]+\zeta_{a} \cdot \nabla\left(\frac{d \psi}{d t}\right)+(\nabla \times F) \cdot \nabla(\psi) .
$$

In meteorology $\psi$ is taken to be the potential temperature, although it can be equally well taken to be the specific entropy or any other function of potential temperature (Hoskins et al., 1985). The original Ertel's dry air formulation indeed corresponds to the case $\psi=\theta$, where the dry-air potential temperature is equal to

$$
\theta=T\left(\frac{p_{0}}{p}\right)^{K}
$$

Substituting, $\psi$ by $\theta$ in equation 1, results into the original Ertel (1942) PV formulation

$$
P V(\theta)=\frac{1}{\rho} \zeta_{a} \cdot \nabla(\theta) .
$$

The above PV formulation is often used to study the thermodynamic properties of moist atmosphere, though it is based on $\theta$ and not on a moist counterpart (Marquet, 2014). Nevertheless, Ertel PV is not conserved when latent heat release is taken into account in a moist atmosphere (Cao \& Cho, 1995; Mofor \& Lu, 2008). Replacing $\psi$ by $\theta$ in equation 2 , results

$$
\rho \frac{d}{d t}[P V(\theta)]=\frac{1}{\rho^{2}} \nabla(\theta) \cdot[\nabla(\rho) \times \nabla(p)]+\zeta_{a} \cdot \nabla\left(\frac{d \theta}{d t}\right)+(\nabla \times F) \cdot \nabla(\theta)
$$

Since $\theta$ can be expressed as a function of total density and total pressure only, according to the equation of state for the dry-air,

$$
\begin{gathered}
p=\rho R_{d} T=\rho R_{d} \theta\left(\frac{p}{p_{0}}\right)^{k}, \\
\theta(\rho, p)=\frac{p}{\rho R_{d}}\left(\frac{p_{0}}{p}\right)^{k}
\end{gathered}
$$


its use as thermodynamic variable in computation of PV leads to the annihilation of the solenoidal term in the first line in the R.H.S of equation 5 (Schubert et al., 2001; Marquet, 2014). Marquet (2014) argue that, for adiabatic, reversible and frictionless motions of dry air, the second line in the R.H.S of equation 5 also cancels out. This is due to the fact that the term depends on the material derivative of $\theta$ and is equal to zero since the dry air entropy

$s=c_{p d} \ln (\vartheta)+\mathrm{C}$ corresponds to the property $\frac{d \theta}{d t}=\left(\frac{\theta}{c_{p d}}\right) \frac{d s}{d t}=0$. The last term of equation 5 depends on the curl

of the friction force and it vanishes for frictionless motion. Therefore the material derivative of equation 5 is zero for, $\psi=\theta$ and during the reversible, adiabatic and frictionless motion of a parcel of dry air.

In order to avoid these drawbacks, moist version of the potential vorticity was first defined by Bennetts and Hoskins (1979) as.

$$
\operatorname{MPV}\left(\theta_{e}\right)=\frac{1}{\rho} \zeta_{a} \cdot \nabla\left(\theta_{e}\right)
$$

where $\theta$ is replaced with equivalent potential temperature $\theta_{e}$. However, Schubert et al (2001) have argued that MPV is conservative only in moist adiabatic and frictionless processes. Indeed, various moist formulations of PV have been built and equation 1 tested, with $\psi$ replaced by any of the wet bulb $\left(\theta_{w}^{\prime}\right)$, moist entropic $\left(\theta_{s}^{*}\right)$, and virtual potential temperatures $\left(\theta_{v}\right)$. However, the atmosphere is non-uniformly saturated; therefore none of the above mentioned potential temperatures fulfil the demand to verify, at the same time, a moist and dry air conservative property and an invertibility principle.

To overcome that drawback, Gao et al. (2004) derived a Generalized Moist Potential Vorticity (GMPV) by replacing $\theta$ with a Generalized Potential Temperature (GPT) $\theta^{*}$, where GPT is written as

$$
\theta^{*}(T, p, q)=\theta \exp \left(\frac{L q_{s}}{c_{p} T}\left(\frac{q}{q s}\right)^{k}\right) .
$$

, where $q$ and $q_{s}$ is the specific humidity and saturated specific humidity respectively, $\left(\frac{q}{q s}\right)^{k}$ is a condensation probability function. It is noticeable that in the case of absolutely dry atmosphere where $q=0$, equation 9 reduces to $\theta^{*}(T, p, q)=\theta$, while in completely saturated atmosphere where $q=q_{s}$ it reduces to $\theta^{*}(T, p, q)=\theta_{e}=$ $\theta \exp \left(\frac{L q_{s}}{c_{p} T}\right)$. In more realistic atmosphere which is neither saturated nor un-saturated, the introduction of condensation probability function fixes the discontinuity of latent heat term due to the impact of water phase changes in the thermodynamic equation. Therefore a smooth transition from completely dry atmosphere and saturated atmosphere is achieved through the change of specific humidity from $q$ to $q_{s}$.

The GPT has been successfully tested in computation of MPV (e.g. Gao et al., 2004; Mofor \& Lu, 2008; Shuai et al., 2014), and found the solenoidal term does not cancel out in the MPV tendency equation. However, Gao et al (2004) noted some limitations of applicability of the condensation density function in regions of no condensation or lower relative humidity conditions.

More recently Marquet (2014) derived a new MPV using a specific entropy formulation expressed in terms of moist-air entropy potential temperature $\left(\theta_{s}\right)$ as:

$$
\operatorname{MPV}\left(\theta_{s}\right)=\frac{1}{\rho} \zeta_{a} \cdot \nabla\left(\theta_{s}\right)
$$

$\theta_{s}$, is valid for a general mixing of dry air, water vapour and all possible condensed water species. It is mentioned in Marquet (2014) that $\theta_{s}$ verifies the same conservative properties as the moist entropy, even for varying dry air or total water content. The moist formulation for $\theta_{s}$ is equal to the dry formulation $\theta$ if dry air is considered and it verifies new properties valid for the moist air cases, both saturated or under-saturated ones. Based on the literature, reviewed in this study, moist air entropy potential temperature $\theta_{s}$ is the only one which represents the moist-air entropy in all circumstance, including in non-adiabatic and very moist regions. For these reasons, only MPV computed from replacing $\psi$ with $\theta_{s}$ in equation 1 should be used to represent the moist-air PV in the moist lower troposphere. 
However, MPV has its own dynamic limitations (Ratana et al., 2013). It does not contain vorticity along the isentropic surfaces and thus cannot reflect atmospheric vorticity in three dimensions (Ratana et al., 2013). In large scale atmospheric flow the absolute vorticity and gradient of temperature are nearly vertical. This makes the MPV dominant parameter to describe large scale convective systems. The vorticity along the horizontal isentropic surfaces is ignored. This vorticity is not important in development of large scale convective systems. In mesoscale convective systems the isentropic surfaces becomes nearly vertical when convection and latent heat release is taken into account (Ratana et al., 2013). The potential temperature gradient becomes nearly horizontal. MPV therefore can represent vorticity perpendicular to isentropic surface and remove the vorticity along isentropic surface.

In meso scale convective system the ignored vertical component of vorticity play a profound role in development and formation of rainfall events. Moreover, the Coriolis parameter is very small over the tropics such that equatorial flows, especially two dimensions equatorial flows may not be explained by any version of MPV as Gao et al (2004) argued. Zi-feng and Hui, (2012) indicated that MPV is mainly in the horizontal direction over the tropics since the vertical gradient of temperature is small compared to the horizontal gradient of temperature. Gao et al (2004) suggested the use of Convective Vorticity Vector (CVV) while studying deep convection over the tropics. However CVV is defined using the gradient of equivalent potential temperature $\theta_{e}$ which is conserved only under moist adiabatic and frictionless atmospheric flow (Luhunga et al., 2016). Since the atmosphere is nonuniformly saturated, CVV cannot be used to study non-uniformly saturated atmospheric flow and fulfill at the same time the dry air and moist air conservative property (Luhunga et al., 2016).

In this study the Moist Potential Vorticity Vector (MPVV) defined as the cross product of absolute vorticity and the gradient of moist air entropic potential temperature is analyzed on its ability to diagnose the occurrence of rainfall events over different regions in Tanzania. The most important advantage of MPVV is the coupling of horizontal isentropic and the absolute vorticity that obey the law of conservation of angular momentum. It is expected that MPVV can detect the areas received rainfall events over different regions in Tanzania. Furthermore the magnitude of the MPVV that include the three components of MPVV is anticipated to describe the location received rainfall correctly.

\section{Data and Methodology}

The Weather Research and Forecasting (WRF) model, jointly developed by the National Oceanic and Atmospheric Administration (NOAA) and National Centre for Atmospheric Research (NCAR) was used in this study. The WRF model is a non-hydrostatic mesoscale NWP model, fully compressible and has terrain following sigma coordinates (Ratna et al., 2013). It features multiple dynamical cores, a 3-dimensional variation and 4- dimensional (3DVAR and 4DVAR) data assimilation system, and a software architecture allowing for computational parallelism and system extensibility. WRF is suitable for a broad spectrum of applications across scales ranging from meters to thousands of kilometres (Wang et al., 2008).

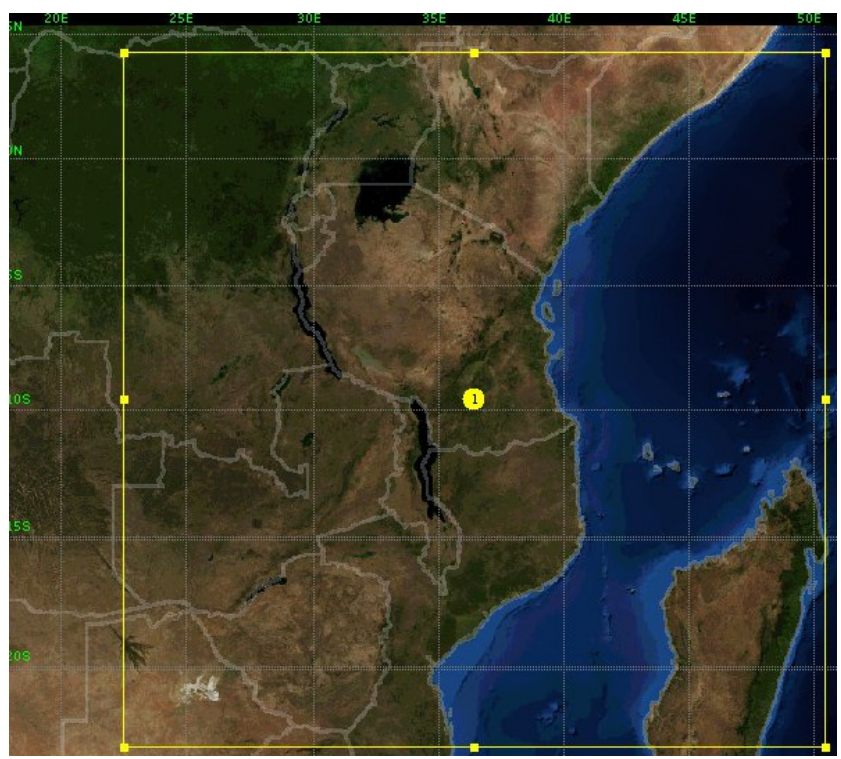

Figure 1. The topographical map indicating the domain where WRF was set 
The WRF model version 3.3.1 was set-up over East Africa domain $\left(-25^{\circ} \mathrm{S}\right.$ to $\left.4^{0} \mathrm{~N} ; 23^{0} \mathrm{E}-52^{0} \mathrm{E}\right)$ on a horizontal resolution of $15 \mathrm{~km}$, with 28 vertical levels (Figure 1 ).

The WRF model was forced with initial and boundary conditions from the National Centre for Environmental Prediction (NCEP) global forecast system (GFS) dataset with a $\left(0.5^{\circ} \times 0.5^{\circ}\right)$ space resolution. The input data have a time interval of three hours. The simulations were initiated at $00 \mathrm{~h}$ UTC and run for 48 hours ahead and output was archived for every 1 hour. The model was set to simulate dynamic and thermodynamic meteorological variables that include wind speeds (zonal, meridional and vertical components), temperature, and relative humidity at different pressure levels. These data were used to compute MPVV at 925, and 850hPa pressure levels.

\subsection{Description of the Diagnosis of Rainfall Events}

\section{Analysis}

The first variable in MPVV computation is the moist-air entropy potential temperature $\theta_{s}$, defined by Marquet (2011) as

$$
\theta_{s} \equiv\left(\theta_{s}\right)_{1}\left(\frac{T}{T_{r}}\right)^{\lambda q_{t}}\left(\frac{p}{p_{r}}\right)^{-k \delta q_{t}}\left(\frac{r_{r}}{r_{v}}\right)^{\gamma q_{t}} \frac{\left(1+\eta r_{v}\right)^{k\left(1+\delta q_{t}\right)}}{\left(1+\eta r_{r}\right)^{k \delta q_{t}}}
$$

where $\left(\theta_{s}\right)_{1}$ is written as

$$
\left(\theta_{s}\right)_{1}=\theta \exp \left(\Lambda_{r} q_{t}\right) \exp \left(-\frac{L_{v} q_{l}+L_{s} q_{i}}{c_{p d} T}\right)
$$

$\Lambda_{r}=\frac{\left(s_{v}^{0}-s_{d}^{0}\right)}{c_{p d}} \approx 5.87$ is a key quantity. It depends on the standard entropies of water vapour and dry air $\left(s_{v}^{0}\right)$ and $\left(s_{d}^{0}\right)$ (Marquet, 2011). $\left(\theta_{s}\right)_{1}$ is a good approximation of $\theta_{s}$. For detailed derivation of $\theta_{s}$ please refer to (Marquet, 2011, 2014, 2015).

The second variable used in MPVV computation is the air density which is defined as

$$
\rho=\frac{p}{\theta(\rho, p) R_{d}}\left(\frac{p_{0}}{p}\right)^{k}
$$

where $p_{0}$ is atmospheric pressure at reference level, $p$ is atmospheric pressure (in Pa) at different level, $R_{d}$ is specific gas constant for dry air $\theta(\rho, p)$ is potential temperature and $k=\frac{R_{d}}{C_{p}}, C_{p}$ is specific heat capacity at constant pressure.

The third variable used in MPVV computation is the absolute vorticity defined as

$$
\zeta_{a}=-\frac{\partial v}{\partial z} \boldsymbol{i}+\frac{\partial u}{\partial z} \boldsymbol{j}+(\zeta+f) \boldsymbol{k},
$$

where relative vorticity ( $\zeta)$ is defined as $\left(\frac{\partial v}{\partial x}-\frac{\partial u}{\partial y}\right) \boldsymbol{k}+\frac{u}{a} \tan (\varphi), a$ is the radius of the earth and $\varphi$ is the latitude, $f$ is the coriolis parameter defined as $f=2 \Omega \sin (\varphi), \mathrm{u}$ and $\mathrm{v}$ are the zonal and meridional wind components, respectively and $\mathrm{z}$ is the vertical distance.

$\overrightarrow{M P V V}$, can now be defined as

$$
\overrightarrow{M P V V}\left(\theta_{s}\right)=\frac{1}{\rho}\left(\begin{array}{c}
-\frac{\partial v}{\partial z} \\
\frac{\partial u}{\partial z} \\
(\zeta+f)
\end{array}\right) \times\left(\begin{array}{c}
\frac{\partial \theta_{s}}{\partial x} \\
\frac{\partial \theta_{s}}{\partial y} \\
\frac{\partial \theta_{s}}{\partial z}
\end{array}\right)=\frac{1}{\rho}\left(\begin{array}{c}
\frac{\partial u}{\partial z} \frac{\partial \theta_{s}}{\partial z}-(\zeta+f) \frac{\partial \theta_{s}}{\partial y} \\
\frac{\partial v}{\partial z} \frac{\partial \theta_{s}}{\partial z}+(\zeta+f) \frac{\partial \theta_{s}}{\partial x} \\
-\frac{\partial v}{\partial z} \frac{\partial \theta_{s}}{\partial y}-\frac{\partial u}{\partial z} \frac{\partial \theta_{s}}{\partial x}
\end{array}\right)=\left(\begin{array}{c}
\overrightarrow{M P V V}_{x} \\
\overrightarrow{M P V V_{y}} \\
\overrightarrow{M P V V_{z}}
\end{array}\right)
$$

Considering the hydrostatic equilibrium $\partial / \partial z=-\rho g \partial / \partial p$, Eq. 15 can be re-written as

$$
\begin{gathered}
\text { Zonal component }{\overrightarrow{M P V V_{x}}}=\rho g^{2} \frac{\partial u}{\partial p} \frac{\partial \theta_{s}}{\partial p}-\frac{(\zeta+f)}{\rho} \frac{\partial \theta_{s}}{\partial y}, \\
\text { Meridional component }{\overrightarrow{M P V V_{y}}}=\rho g^{2} \frac{\partial v}{\partial p} \frac{\partial \theta_{s}}{\partial p}+\frac{(\zeta+f)}{\rho} \frac{\partial \theta_{s}}{\partial x},
\end{gathered}
$$




$$
\text { Vertical component }{\overrightarrow{M P V V_{z}}}_{=}=g\left(\frac{\partial v}{\partial p} \frac{\partial \theta_{s}}{\partial y}+\frac{\partial u}{\partial p} \frac{\partial \theta_{s}}{\partial x}\right)=g\left(\left(\frac{\partial v}{\partial y}+\frac{\partial u}{\partial x}\right) \frac{\partial \theta_{s}}{\partial p}\right)=D \cdot g \frac{\partial \theta_{s}}{\partial p},
$$

where $\mathrm{D}$ is divergence term, $\mathrm{x}$ and $\mathrm{y}$ are, respectively, the zonal and meridional distances

The magnitude of $\overrightarrow{M P V V}$ is written as

$$
|\overrightarrow{M P V V}|=\sqrt{\left(\overrightarrow{M P V V}_{x}\right)^{2}+\left(\overrightarrow{M P V V}_{y}\right)^{2}+\left(\overrightarrow{M P V V}_{z}\right)^{2}} .
$$

It should be noted that all the components and the magnitude of MPVV includes both the dynamic and thermodynamic parameters. This makes them important in describing any atmospheric flows, particularly those associated with the formation of rainfall events.

\section{Results and Discussion}

\subsection{The Rainfall Incidence on $8^{\text {th }}$ May 2017 and Disastrous Impacts}

On $8^{\text {th }}$ and $9^{\text {th }}$ of May 2017, many parts of Tanzania received rainfall. Regions over the Northern coast of Tanzania (Tanga, Dar Es Salaam, and Zanzibar) received heavy rainfall that triggered flooding events over those regions. Tanga region received 24 hour rainfall accumulation of $316 \mathrm{~mm}$ of rainfall, which was the highest recorded rainfall since year 1949. Pemba Island (northern part of Zanzibar) received 24 hour rainfall accumulation of $164.5 \mathrm{~mm}$, and Uguja Island (southern part of Zanzibar) received $58.7 \mathrm{~mm}$ of rainfall in 24 hours.

The satellite images indicate cloud bands over the northern coast on $8^{\text {th }}$ and $9^{\text {th }}$ May 2017 (Figure 2). These clouds are convective low level clouds that may have influenced the heavy rainfall events over the northern coast of Tanzania. Heavy rainfall that influenced devastating and catastrophic flooding events were reported in Tanga where major transport networks were destroyed by floods and about seven people were officially reported dead due to their homes being covered with water. Many vehicles in Tanga were found covered with sandstone, tree branches and stones.

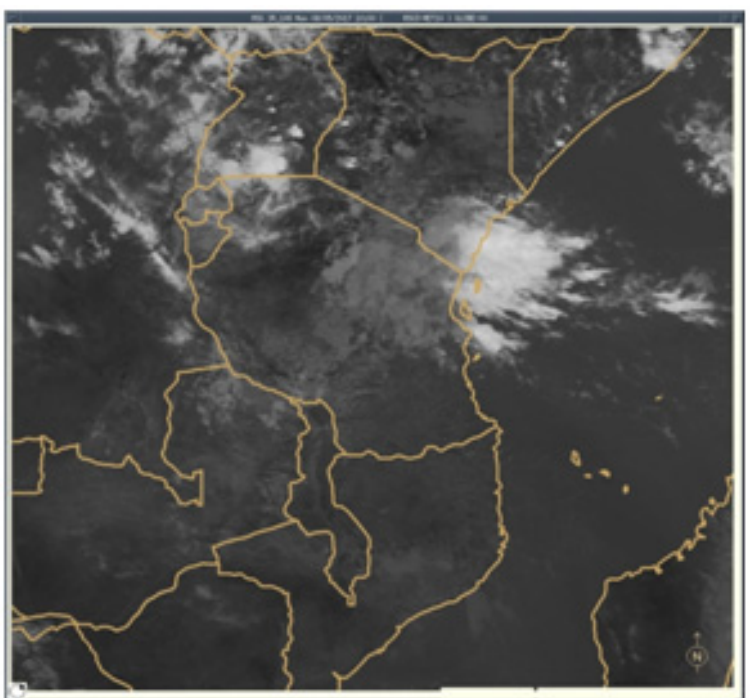

(a) Satellite image on 08th May 2017 at 1000UTC

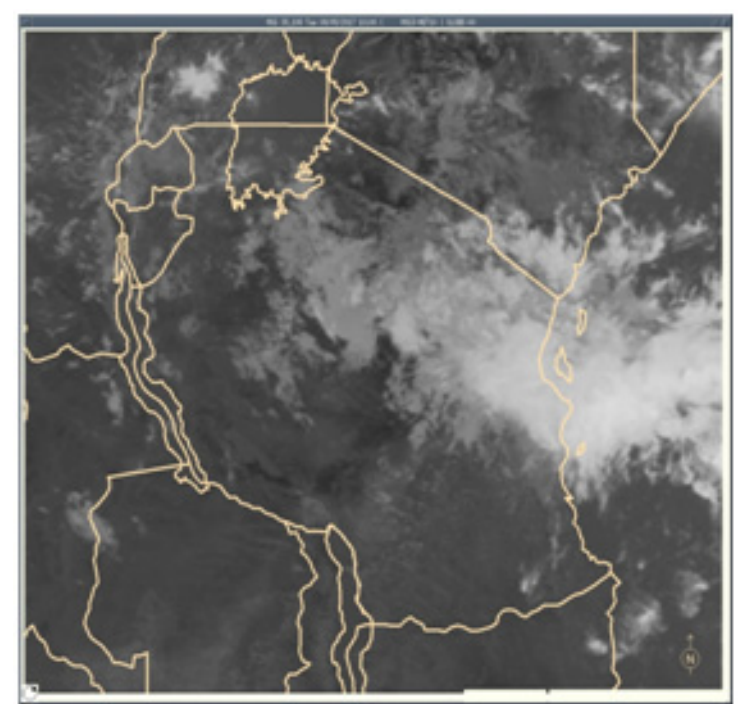

(b) Satellite image on 09th May 2017 at 1000UTC

Figure 2. the satellite image from Infra-red channel, indicating cloud bands over the northern coast of Tanzania

\subsection{An Overview of the Synoptic Systems at 0600Z on $8^{\text {th }}$ and $9^{\text {th }}$ May 2017}

The analysis of synoptic system presented in Figure 3 indicates that on the $8^{\text {th }}$ May 2017, a clear northerly trough at $850 \mathrm{hPa}$ was situated over the Indian Ocean close to the Coast of Somalia. This trough strengthened on the $9^{\text {th }}$ of May 2017 (Figure 3b) and influenced development of strong convection over the regions of the Northern Coast of Tanzania and over the Islands of Zanzibar. The north easterlies and south easterlies flow of the wind coupled with high relative humidity over the Northern Coast of Tanzania and the Island of Zanzibar (Figure 4) influenced the heavy rainfall events over those areas. The existence of the trough was also seen over the Lake Victoria basins. This influenced convective activities over those areas. 


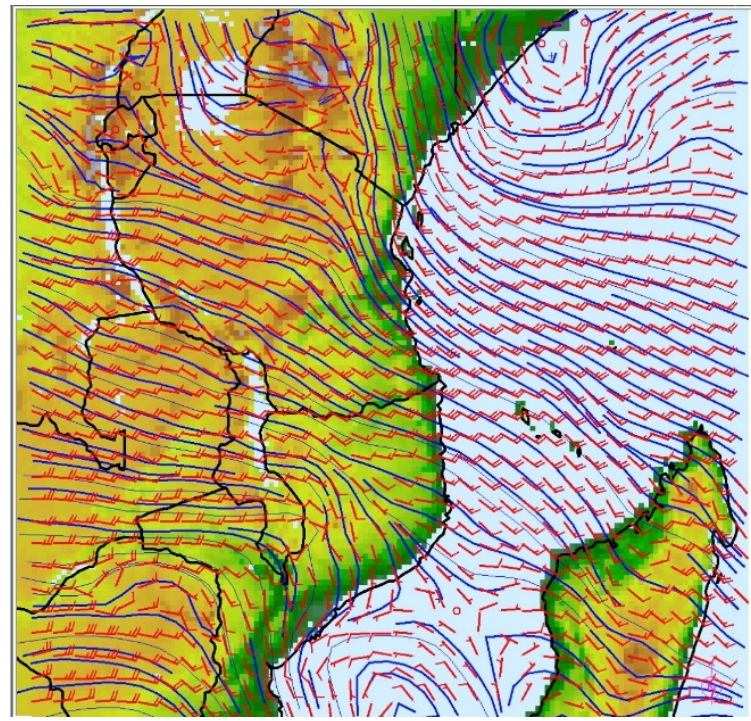

(a)

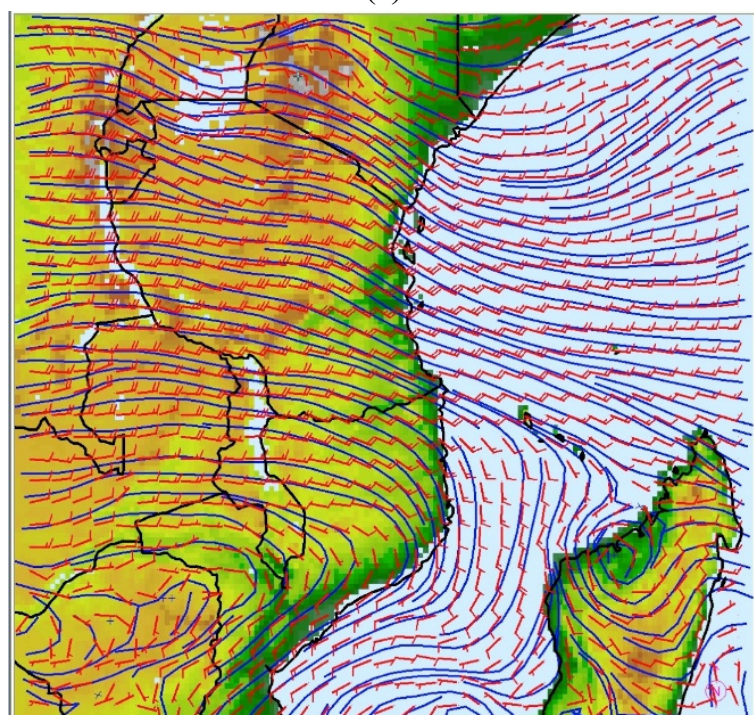

(c)

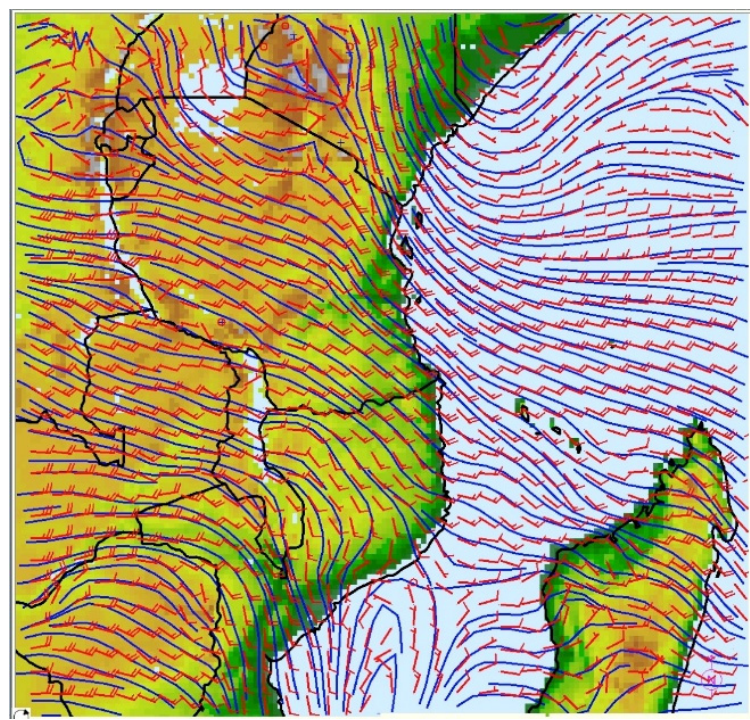

(b)

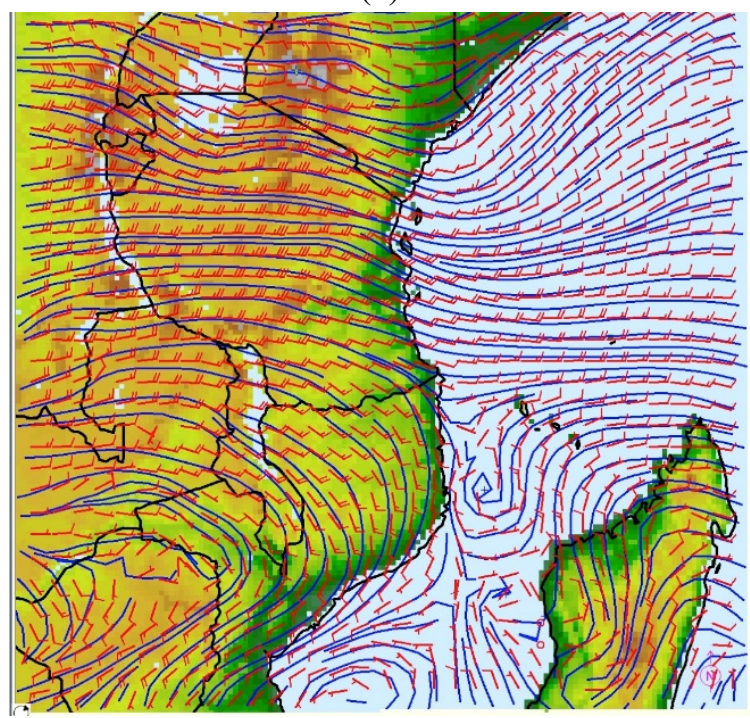

(d)

Figure 3. Wind vector in $(\mathrm{m} / \mathrm{s})$ at $850 \mathrm{hPa}$ (the top panel) and at $700 \mathrm{hPa}$ (the bottom panel) at $0600 \mathrm{Z}$ (a)-(c) on the $8^{\text {th }}$ and (b)-(d) on the $9^{\text {th }}$ May 2017

\subsection{WRF forecast}

The WRF model indicated strong rainfall signal over northern coast of Tanzania (Figure 5).

\subsection{MPVV Forecast}

In this study the analysis to test the usefulness of MPVV as a diagnostic variable of rainfall events over different regions in Tanzania is presented. Figure 5 presents the distribution of 24-hour cumulated rainfall over different regions in Tanzania as forecasted by the WRF model on the $08 / 5 / 2017$. From this figure, it can be seen that rainfall is distributed over the northern coast, northeastern highlands, northern, western regions, parts of southern regions and southwestern highlands. Heavy rainfall of more than $50 \mathrm{~mm}$ was forecasted over northern coast and over the island of Zanzibar. The forecasted 24 hour cumulated rainfall from the WRF partly collocated with rainfall estimate from satellite observation (Figure 5). However, satellite estimates indicated that the entire coastal region received rainfall. Heavy rainfall was estimated over the northern coast similar to WRF forecast.

The distribution of MPVV (Fig 7 and 8) portrayed similar patterns to that of rainfall (Figure 5 and 6 ). The MPVV values at $925 \mathrm{hPa}$ (Figure 7) were mostly positive over most parts of the country. However, maximum values of 
MPVV were concentrated over the areas that received heavy rainfall (the northern coast, particularly over Tanga, Dar es Salaam, and the Island of Zanzibar).

The distribution of the magnitude and zonal component of MPVV at $925 \mathrm{hPa}$ indicates a band of positive values of MPVV over the entire coastal regions (Figure 7-8). Positive values of MPVV are observed over the entire coastal regions, parts of southwestern highlands western regions northern regions. Maximum values of MPVV are seen over Zanzibar, Tanga and Dar es Salaam. This distribution almost collocates with the distribution of rainfall (Figure 5 and 6). The maximum values of MPVV situated over the northern coast were responsible for the heavy rainfall events happened over those areas (Figure 6).

The spatial distribution of the magnitude of MPVV at $850 \mathrm{hPa}$ collocates with the distribution of rainfall, particularly over the coastal regions and over the Islands of Zanzibar. The band of positive values oriented in south-east direction is situated close to the southern coast of Tanzania. This may have influenced rainfall activities over those areas. Moreover the small bands of positive MPVV from magnitude of MPVV at $850 \mathrm{hPa}$ are seen between Pemba and Unguja Islands (Figure 10). This might have contributed to heavy rainfall events over those areas. The zonal component of MPVV at $850 \mathrm{hPa}$ (Figure 11) indicates a band of maximum values of MPVV over Zanzibar, Small band of maximum value of MPVV from the zonal component is seen over southwestern highlands of Tanzania. The distribution of zonal components of MPVV from the zonal components shows similar pattern with the forecasted rainfall from WRF model and that from satellite estimates. The Meridional component of MPVV at $850 \mathrm{hPa}$ share little similarity with the forecasted rainfall and even with satellite estimated rainfall. The valuable information from Figure 11 is that the maximum values of MPVV are close to regions received rainfall events.

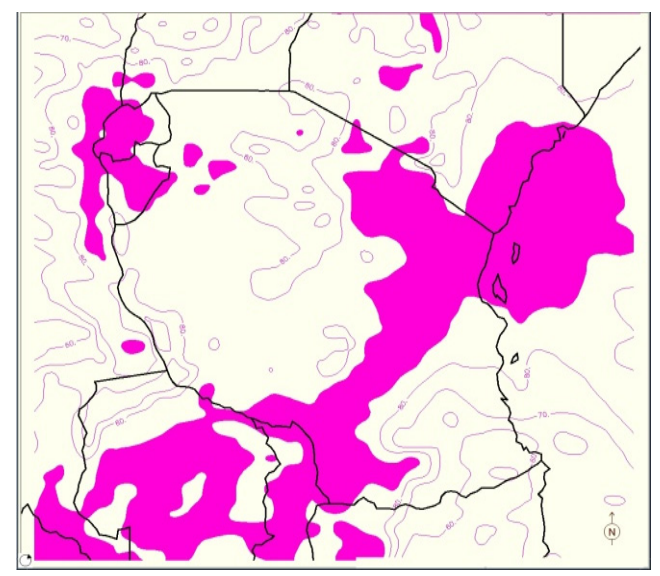

(a)

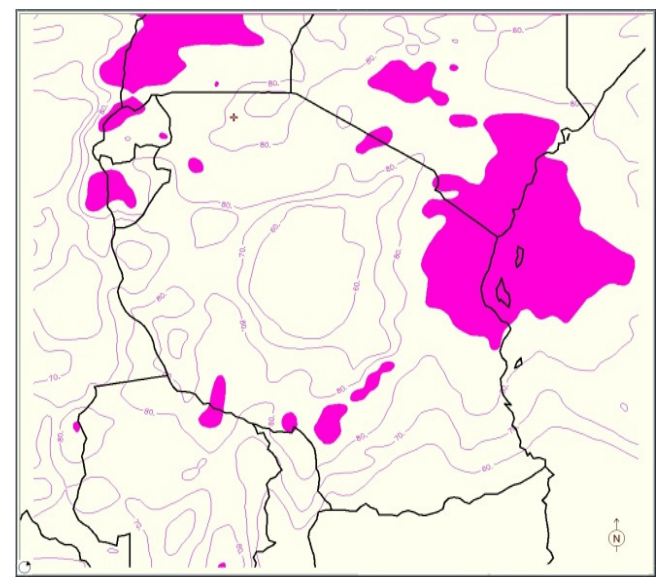

(c)

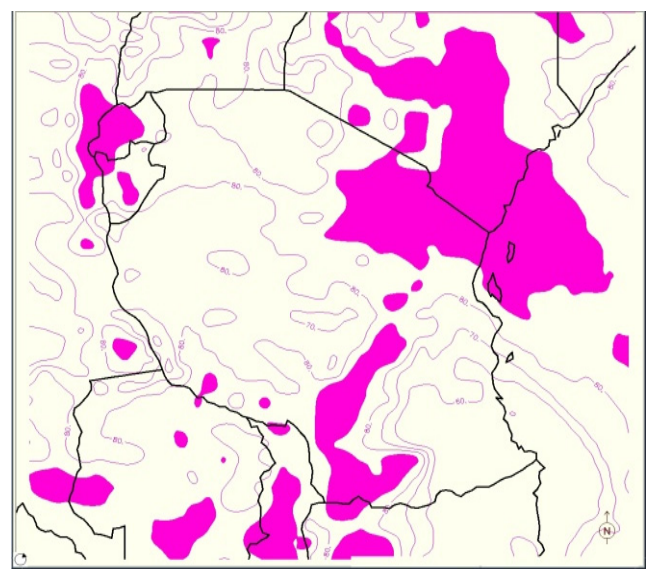

(b)

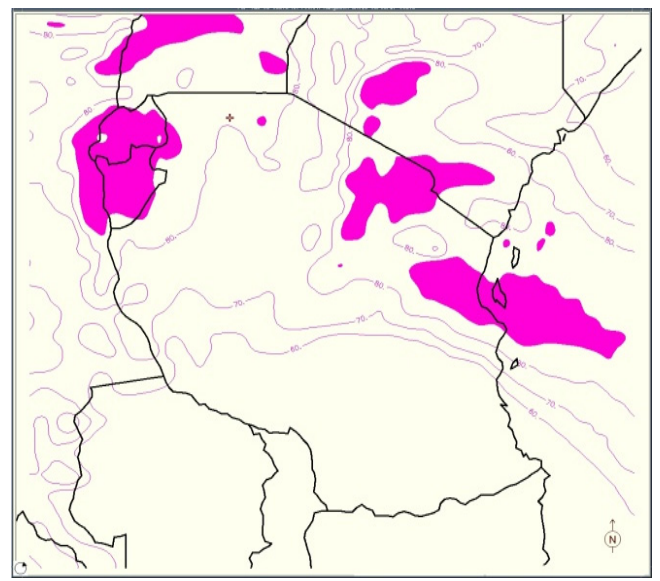

(d)

Figure 4. Relative humidity in (\%) at $850 \mathrm{hPa}$ (the top panel) and at $700 \mathrm{hPa}$ (the bottom panel) at $0600 \mathrm{Z}$ (a)-(c) on the $8^{\text {th }}$ and (b)-(d) on the $9^{\text {th }}$ May 2017 


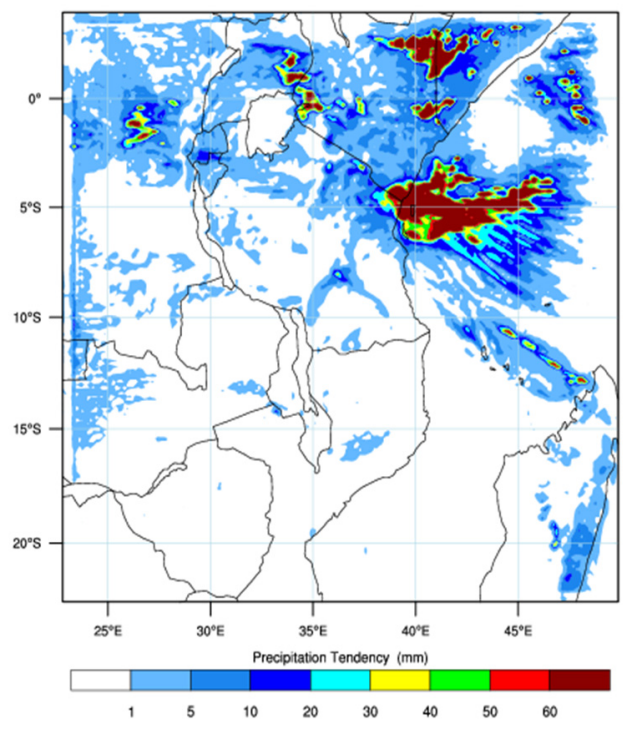

Figure 5. WRF 24 hours rainfall forecast on $08 / 5 / 2017$

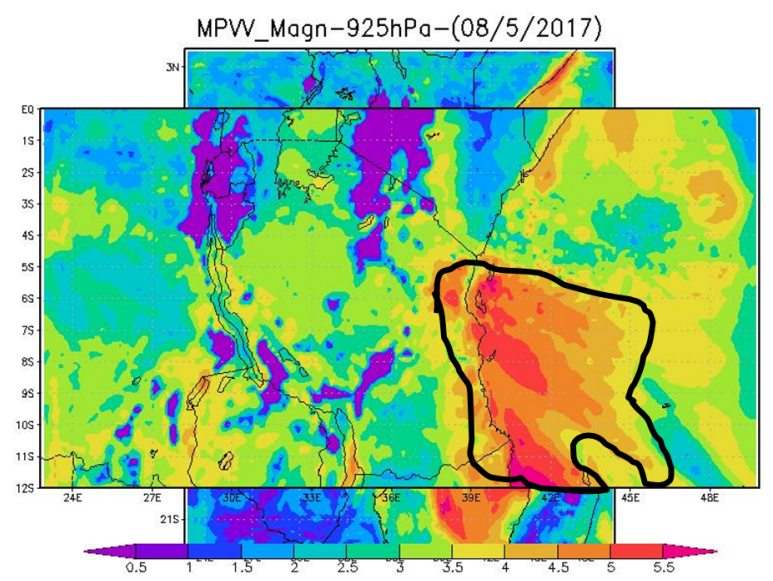

Figure 7. the magnitude of MPVV in PV-units at $925 \mathrm{hPa}$

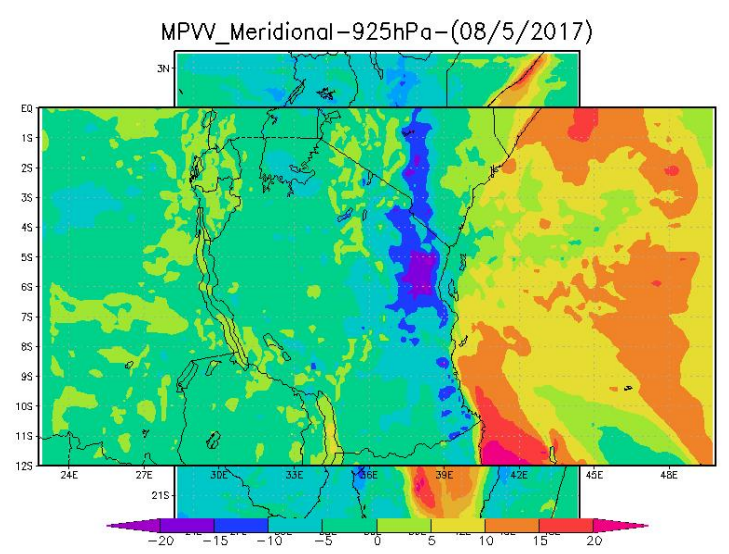

Figure 9. the meridional component of MPVV in PVunits at $925 \mathrm{hPa}$

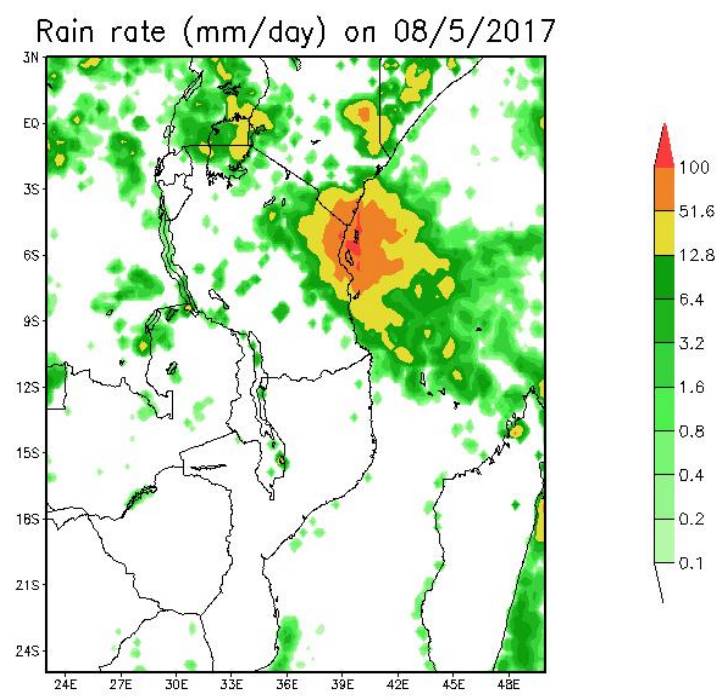

Figure 6. Rainfall (mm/day) on 08/5/2017 estimated from satellite observation

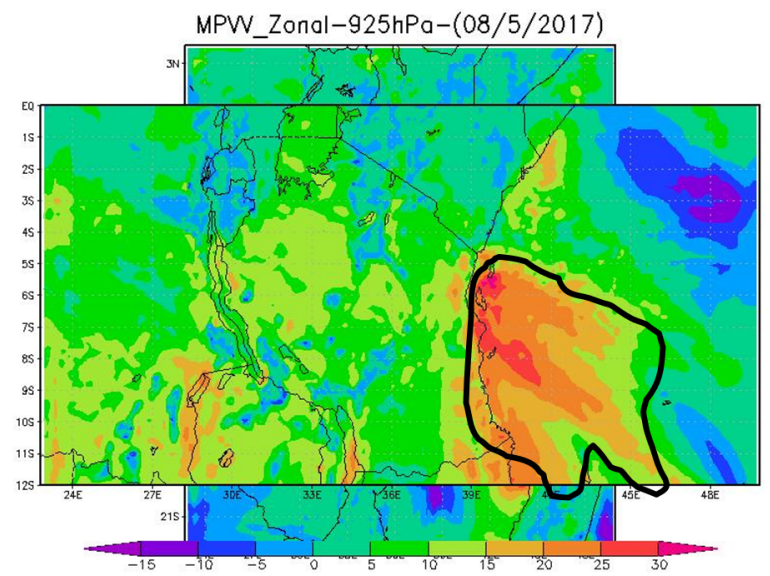

Figure 8. the zonal component of MPVV in PV-units at $925 \mathrm{hPa}$

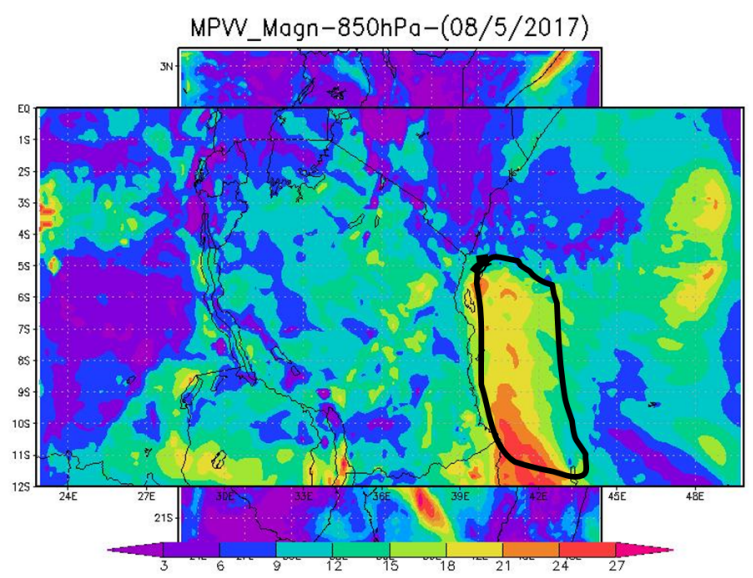

Figure 10. the magnitude value of MPVV in PVunits at $850 \mathrm{hPa}$ 


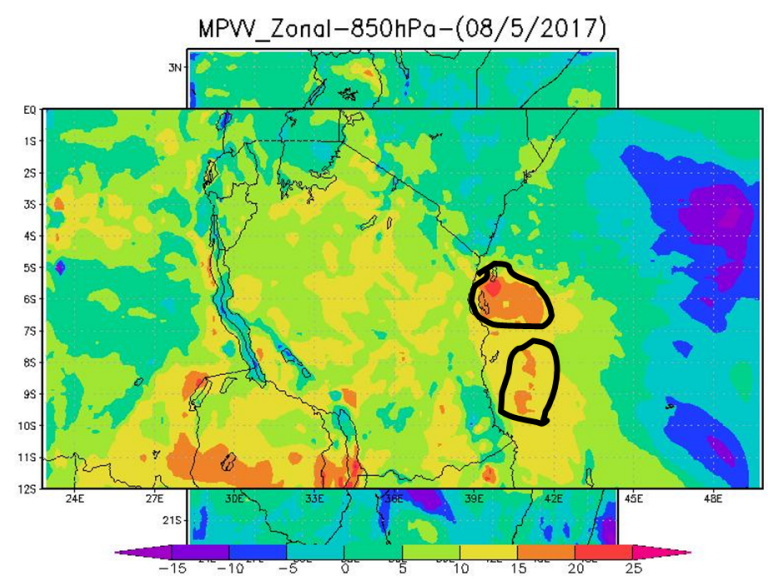

Figure 11. the zonal component of MPVV in PV-units at $850 \mathrm{hPa}$

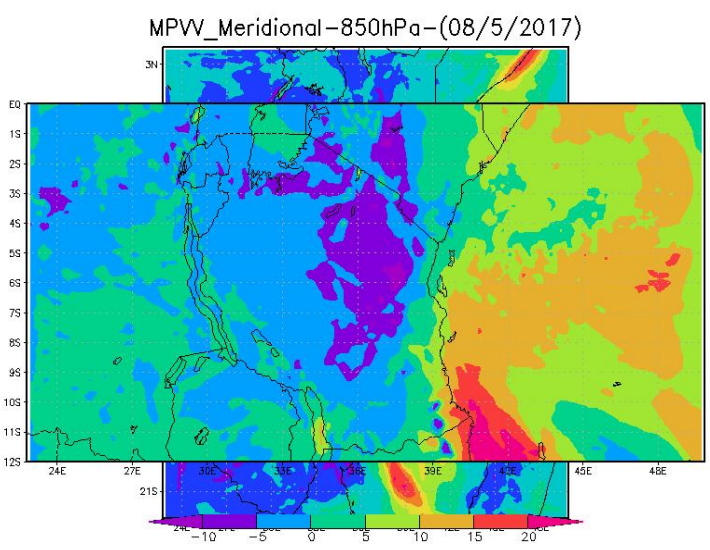

Figure 12. the meridional component of MPVV in PV-units at $850 \mathrm{hPa}$

\section{Conclusion and Recommendation}

In this study, we presented the utility of MPVV in diagnosis of rainfall events over different regions of Tanzania. The main purpose of the paper was to compute MPVV and compare the maps of MPVV with forecasted rainfall from WRF and validate with rainfall estimates from satellite observations. One case study happened from $08^{\text {th }}$ to $09^{\text {th }}$ May 2017 has been analyzed where many regions especially over the entire coast of Tanzania received rainfall. Moreover from $08^{\text {th }}$ to $09^{\text {th }}$ May 2017 the northern coast of Tanzania received heavy rainfall events, especially over Tanga region where $364 \mathrm{~mm}$ of rainfall was recorded for the first time since 1964 . The Islands of Zanzibar received heavy rainfall events that lead to destruction of transportation networks and paralyzed social economical activities over the Islands.

The MPVV was computed using the gradient of moist air entropy potential temperatures defined by Marquet (2011 and 2014). This temperature is conservative under dry and moist atmosphere. The variables used in computation of MPVV were derived from the Weather Research and Forecasting (WRF). Dynamical variables and thermodynamic variables (wind speed, temperatures, relative humidity, and atmospheric pressure) at $1000 \mathrm{hPa}$, and $850 \mathrm{hPa}$ were used to compute MPVV at $925 \mathrm{hPa}$. Moreover, wind speed, temperatures, relative humidity, and atmospheric pressure at $925 \mathrm{hPa}$, and $800 \mathrm{hPa}$ were used to compute MPVV at $850 \mathrm{hPa}$.

It is important to note that the MPVV presented in this study are from two levels $(925 \mathrm{hPa}$ and $850 \mathrm{hPa})$. This is due to the fact that the rainfall event on $8^{\text {th }}$ of May 2017 was associated with low level winds and convection was possibly dominated by mechanical zonal wind shears.

The presented results suggest that MPVV can serve as a diagnostic variable of rainfall events, especially heavy rainfall event over different regions in Tanzania. The magnitude of MPVV and the zonal component locate better the areas received rainfall when compared to the meridional component. The vertical component (not shown) indicated the areas received rainfall with maximum values of MPVV. Maximum values of MPVV over the coastal regions were found to coincide with the region received heavy rainfall. This was observed over Tanga and Zanzibar. It should be noted that the areas with maximum values of MPVV do not necessarily coincide with areas received heavy rainfall. It depends on the availability of enough moisture over the area. MPVV will indicate the areas with instability by maximum values. The instability may result to rainfall if there is enough moisture. This has been seen in this study, where over the southern coast of Tanzania where there is maximum values of MPVV from all the components received lower rainfall when compared to the northern coast where maximum values of MPVV associated with high amount of moisture coincided with the region received heavy rainfall. The utility of MPVV therefore is to indicate areas of potential convection, the forecaster need to diagnose the possible source of convection using MPVV maps and compare with moisture maps in diagnosis of rainfall. Furthermore, although there is a good relationship between the spatial distribution of MPVV and rainfall but there is a need to explore the correlation of MPVV with the rainfall intensity to develop robust mathematical relations between MPVV and rainfall. Moreover, there is a need to conduct more research on the usefulness of MPVV in detecting areas received rainfall. 


\section{Acknowledgements}

The authors are grateful to Pascal Marquet from the Meteo-France, CNRM/GMAP/PROC for the useful discussion on computation of his new novelty moist air entropic potential temperature.

\section{Reference}

Bennetts, D. A., \& Hoskins, B. J (1979). Conditional symmetric instability. A possible explanation for frontal rainbands. Q. J. R. Meteorol. Soc., 105(446), 945-962.

Bjerknes, V. (1898a). Uber die Bildung von Circulationsbewegung und Wirbeln in reibungslosen Fliissigkeiten. Videnskabsselskapets Skrifter.I Math. Naturu. Klasse, No. 5

Bjerknes, V. (1898b). Uber einen hydrodynamischen Fundamentalsatz und seine Anwendung besonders auf die Mechanik der Atmosphare und des Weltmeeres. Kgl. Suenska Vetenskapsakad.Handl., 31, No. 4

Cao, Z., \& Cho, H.-R (1995). Generation of moist potential vorticity in extratropical cyclones. J. Atmos. Sci., 52, 3263-3281.

Chang'a, L. B., Yanda, P. Z., \& Ngana, J. (2010). Indigenous knowledge in seasonal rainfall prediction in Tanzania: A case of the South-western Highland of Tanzania. Journal of Geography and egional Planning, 3(4), 66-72.

Ertel, H. (1942). Ein Neuer hydrodynamischer Wirbelsatz. Met. Z., 59, 271-281

Gao, S. T., Wang, X. R., \& Zhou, Y. S. (2004). Generation of generalised moist potential vorticity in a frictionless and moist adiabatic flow, Geophys. Res. Lett., 31, L12113. https:/doi.org/10.1029/2003GL019152.

Haynes, P. H., \& McIntyre, M. E. (1987). On the evolution of vorticity and potential vorticity in the presence of diabatic heating and frictional or other forces. J. Atmos. Sci., 44, 828-841.

Hoskins, B. J., McIntyre, M. E., \& Robertson, A. W. (1985). On the use and significance of isentropic potential vorticity maps. Q.J.R. Meteorol. Soc., 111, 877-946. https://doi.org/10.1002/qj.49711147002

Kijazi, A. L., \& Reason, C. J. C. (2009). Analysis of the 2006 floods over northern Tanzania. International Journal of Climatology, 29, 955-970.

Luhunga, P. M., Djolov, G. D., \& Mutayoba, E. (2016). Moist Potential Vorticity Vector for Diagnosis of Heavy Rainfall Events in Tanzania, 4(09). https://doi.org/10.4236/gep.2016.49010

Marquet P. (2015). An improved approximation for the moist-air entropy potential temperature $\theta$ s. Retrieved from http://arxiv.org/abs/1503.02287

Marquet, P. (2011). Denition of a moist entropic potential temperature. Application to FIRE-I data ights. Q. J. R. Meteorol. Soc., 137(656), 768-791. (M11). Retrieved from http://arxiv.org/abs/1401.1097

Marquet, P. (2014). On the denition of a moist-air potential vorticity.

McIntyre, M. E. (2015). Potential Vorticity In: Gerald R. North (editor-in-chief), John Pyle and Fuqing Zhang (editors). E. Atmos. Sci., 2(2), 375-383.

Mofor, L. A., \& Lu, C. (2008). Generalized moist potential vorticity and its application in the analysis of atmospheric flows. Progress in Natural Science, 19(2009), 285-289. Retrieved from www.sciencedirect.com

Ratana, S. B., Ratnam, J. V., Behera, A. K., Rautenbach, C. J., Ndarana, T., .. Yamagata, T. (2013). Performance assessment of three convective parameterization schemes in WRF for downscaling summer rainfall over South Africa. Clim. Dyn, 42, 2931-2953.

Rossby, C. G. (1939). Relation between variations in the intensity of the zonal circulation of the atmosphere and the displacements of the semi-permanent centers of action. J. Marine Res., 2(1), 38-55.

Wang, W., Barker, D., Bruy`ere, C., Duda, M., Dudhia, J., Gill, D., ... Rizvi, S. (2008). WRF Version 3 Modeling System User's Guide. Retrieved from http://www.mmm.ucar.edu/wrf/users/docs/user guideV3/

Zi-feng, Y., \& Hui, Y (2012). Application of generalized convective vorticity vector in a rainfall process caused by a landfalling tropical depression. J. Trop. Meteor., 18(4), 422-435.

\section{Copyrights}

Copyright for this article is retained by the author(s), with first publication rights granted to the journal.

This is an open-access article distributed under the terms and conditions of the Creative Commons Attribution license (http://creativecommons.org/licenses/by/4.0/). 